\title{
Building Coastal Climate Readiness along the North Shore of Lake Superior
}

KARLY BITSURA-MESZAROS ${ }^{1,2^{*}}$, ALLIE MCCREARY ${ }^{1,2}$, JORDAN W. SMITH $^{1,2}$, ERIN SEEKAMP ${ }^{2}$, MAE A. DAVENPORT ${ }^{3}$, JOHN NIEBER ${ }^{3}$, BRUCE WILSON ${ }^{3}$, DOROTHY H. ANDERSON ${ }^{3}$, CYNTHIA MESSER $^{4}$, MARK KANAZAWA ${ }^{5}$

Volume 3, Spring 2015

http://dx.doi.org/10.3998/mjs.12333712.0003.009

${ }^{1}$ Center for Geospatial Analytics, North Carolina State University, 2800 Faucette Drive, Raleigh, NC 27695

${ }^{2}$ Department of Parks, Recreation and Tourism Management, North Carolina State

University, 2820 Faucette Drive, Raleigh, NC 27695

${ }^{3}$ Department of Forest Resources, University of Minnesota, 1530 Cleveland Avenue N.,

St. Paul, MN 55108

${ }^{4}$ Department of Forest Resources, University of Minnesota Tourism Center, 1420 Eckles

Avenue, St. Paul, MN 55108

${ }^{5}$ Department of Economics, Carleton College, One North College Street, 305 Willis Hall,

Northfield, MN 55057

*Corresponding author: Karly Bitsura-Meszaros, kameszar@ncsu.edu

\section{ABSTRACT}

Nature-based tourism along the North Shore of Lake Superior is a driving force of the region's economy. However, recent survey data reveal a decline in nature-based recreation participation across the North Shore (Kelly 2005). Climate change could exacerbate this trend by altering the conditions of natural resources and recreational infrastructure, thereby impacting the behavior of outdoor recreationists and tourists and, subsequently, the economies of local communities (de Freitas 2008). A multiple-methods research and outreach project is underway to explore how climate change will influence North Shore tourism. This paper explores the project's interdisciplinary approach to determining community climate readiness by integrating the hydro-climatological and socio-economic sciences. The term "community cli- 
mate readiness" refers 1) to local communities' current ability to respond to climatedriven environmental changes (adaptive capacity), and 2) climate-related risks to nature-based recreation resources and tourism destinations (destination risk). The project demonstrates the ability to conduct interdisciplinary research through the integration of hydroclimatic modeling, economic analysis, and social science to determine and improve coastal communities' climate readiness. An overarching goal of the project is to identify opportunities for North Shore nature-based recreation and tourism providers to either mitigate or cope with risks to local recreation resources and tourism destinations. The project's framework will be helpful to practitioners and policy-makers in their own explorations of coastal climate readiness.

\section{Project description}

Coastal tourism along Minnesota's North Shore of Lake Superior (Figure 1) is a driving force of the region's economy. Compared to the state as a whole, the North Shore (i.e., Lake and Cook Counties) relies more heavily on tourism for employment and tax revenues. Tourists engage in a variety of seasonally dependent recreational activities, including hiking, boating, scenic driving, fishing, skiing, and snowmobiling (Kelly 2005). The North Shore is situated in close proximity to Superior National Forest, the Boundary Waters Canoe Area Wilderness, Grand Portage National Monument, and numerous state parks and forests. Tourism is dependent upon these natural amenities, which may be impacted by climate change. Because coastal recreation amenities are particularly vulnerable to climate change (de Frietas 2003), nature-based tourism providers in coastal regions need to be aware of how increasingly variable environmental conditions are likely to impact the perceptions and behaviors of recreationists and tourists.

A multiple-methods research and outreach project is underway to explore how projected hydroclimatic conditions will affect the behaviors of nature-based recreationists and tourists and impact local economies. The project combines hydroclimatic modeling with a diverse array of social science methodologies to estimate probable shifts in the demand for nature-based recreation and tourism under alternative future emissions scenarios. Additionally, decision-support tools are being developed to help local communities visualize the modeling results and enhance their capacity to prepare for and adapt to increasingly variable environmental conditions. Researchers from across the geophysical, economic, social, and spatial sciences are currently engaged in creating the research and outreach project. The project team 


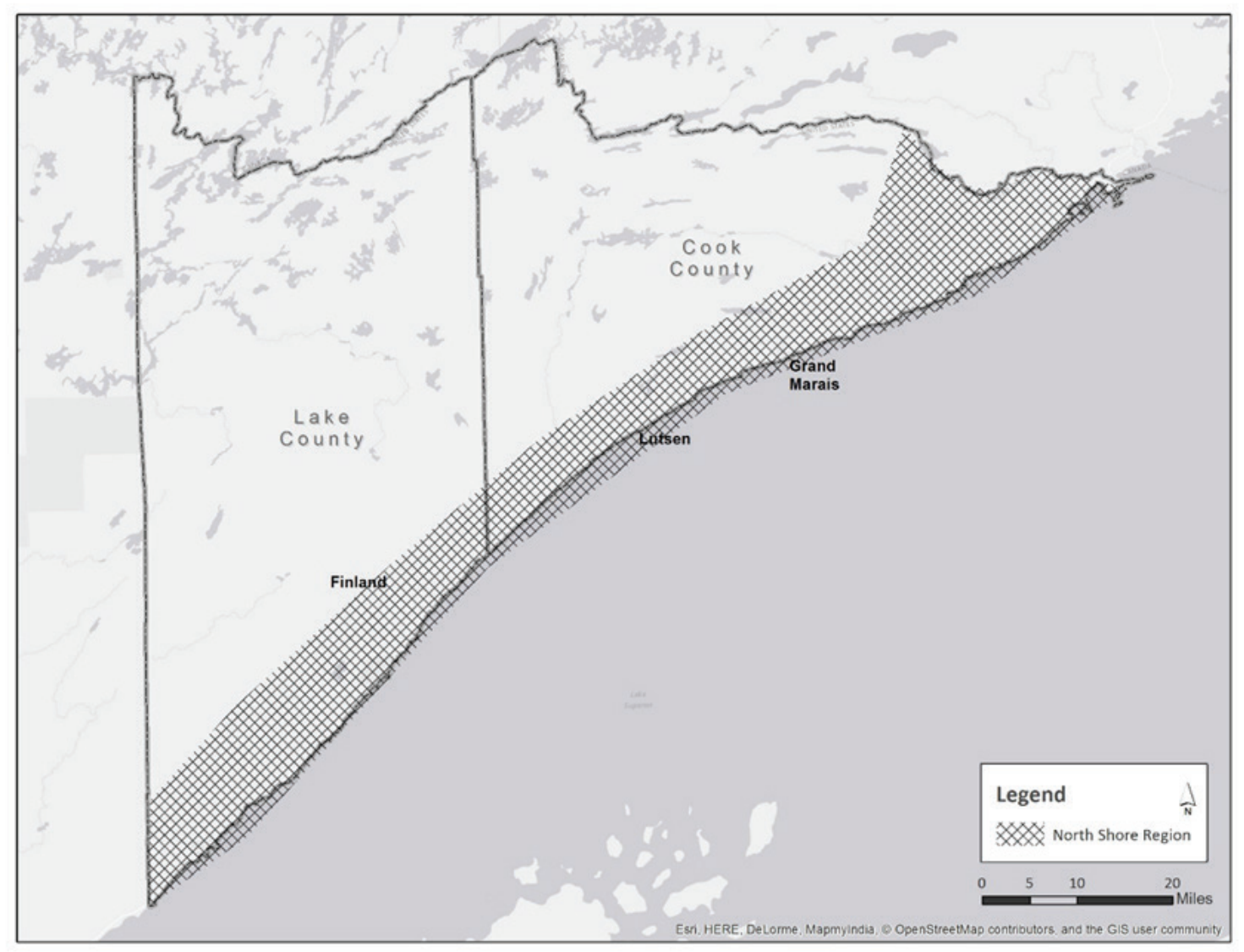

Figure 1. Study area: The Minnesota North Shore of Lake Superior.

consists of members from The University of Minnesota, North Carolina State University, and Carleton College; the Minnesota Sea Grant program funds the project.

The overarching goals of this project (Table 1) are A) to assess the capacity of local communities to adapt to changing climatic conditions using stakeholder interviews, workshops, and a content analysis of local management plans; and B) to determine the risks to nature-based recreation resources and tourism destinations using hydroclimatic modeling, past visitation data, and on-site visitor surveys. Together, the findings from the adaptive capacity and destination risk assessments will allow researchers to work with local communities to (C) develop decision-support tools for adaptive planning by local planners, managers, and decision-makers (Figure 2). This field note describes the project's innovative approach to evaluating the risks to tourism destinations and recreation resources (Goal B).

The complex vulnerability of socioecological systems is best understood through 
TABLE 1. Project Goals, Objectives and Tasks

\begin{tabular}{|c|c|c|}
\hline Goal & Objective & Tasks \\
\hline $\begin{array}{l}\text { A. Assess the capacity of local } \\
\text { communities to adapt } \\
\text { to changing climatic } \\
\text { conditions }\end{array}$ & $\begin{array}{l}\text { 1. Assess the adaptive capacity } \\
\text { of North Shore communities }\end{array}$ & $\begin{array}{l}\text { - Assemble Project Advisory Team (PAT) } \\
\text { - Develop management plan evaluation tool } \\
\text { - Conduct stakeholder interviews, focus groups, } \\
\text { and workshops }\end{array}$ \\
\hline \multirow[t]{3}{*}{$\begin{array}{l}\text { B. Determine the risks to } \\
\text { nature-based recreation } \\
\text { resources and tourism } \\
\text { destinations }\end{array}$} & $\begin{array}{l}\text { 2. Project changes to climate- } \\
\text { related variables affecting } \\
\text { recreation and tourism }\end{array}$ & $\begin{array}{l}\text { - Identify key climate variables (e.g., snow } \\
\text { accumulation, temperature, precipitation, wind } \\
\text { chill, wind speed) likely to affect recreation and } \\
\text { tourism within the study area } \\
\text { - Identify the general circulation models to be } \\
\text { used to project key climate variables under } \\
\text { high, medium, and low climate change } \\
\text { scenarios } \\
\text { - Project key climate variables under high, } \\
\text { medium and low climate change scenarios }\end{array}$ \\
\hline & 3. Analyze past visitation trends & $\begin{array}{l}\text { - Collect visitation data from public recreation } \\
\text { and tourism destinations along the North } \\
\text { Shore } \\
\text { - Regress past climatic conditions (i.e., data on } \\
\text { past key climate variables) against visitation } \\
\text { data }\end{array}$ \\
\hline & $\begin{array}{l}\text { 4. Assess tourists' risk perceptions } \\
\text { and contingent trip-taking } \\
\text { behavior }\end{array}$ & $\begin{array}{l}\text { - Develop on-site survey instrument to assess: } \\
\text { - Tourists' past visitation patterns } \\
\text { - Expenditures on their current trip } \\
\text { - Climate-related risk perceptions specific to the } \\
\text { - North Shore } \\
\text { - Contingent trip-taking behavior } \\
\text { - Substitutability of alternative recreational } \\
\text { - } \text { activities } \\
\text { - Develop winter and summer sampling plan } \\
\text { federal recreation areas and tourism-dependent } \\
\text { businesses. }\end{array}$ \\
\hline $\begin{array}{l}\text { C. Develop and deliver web- } \\
\text { based decision-support } \\
\text { tools for adaptive planning }\end{array}$ & $\begin{array}{l}\text { 5. Create web-based decision- } \\
\text { support tools }\end{array}$ & $\begin{array}{l}\text { - Design, develop and deploy a custom web- } \\
\text { based mapping application that displays: } \\
\text { - Results of the adaptive capacity assessments } \\
\text { - Imagery of current and projected resource } \\
\text { conditions } \\
\text { - Visualizations of the key climate-related } \\
\text { variables used in the climate-hydrological } \\
\text { modeling } \\
\text { - Visualizations of historic and projected } \\
\text { visitation trends }\end{array}$ \\
\hline
\end{tabular}




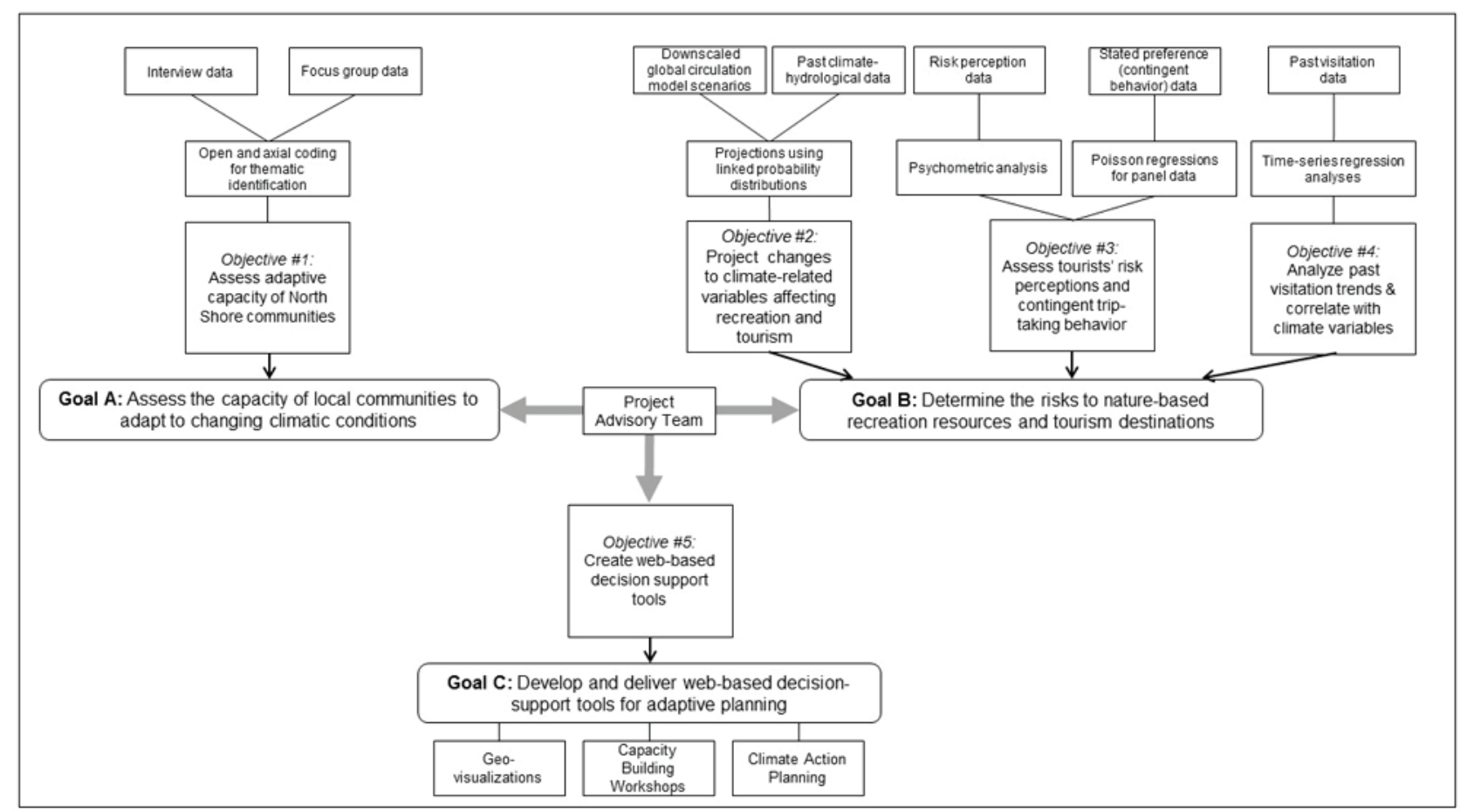

Figure 2. Integrated process for examining tourism destination risk and community adaptive capacity along the North Shore of Lake Superior.

diverse yet complementary methodological approaches (Eakin and Luers 2006). Three actionable objectives were developed to address this complex vulnerability. First, hydroclimatic models were developed (Objective 2) to identify key climatic and environmental variables likely to affect the region's recreation and tourism. Historical monthly visitation data are being regressed on these climate variables to determine the extent to which they are related to recreationists' observed behaviors (Objective 3). Climatic and environmental variables significantly related to visitation are being projected to 2035 under high-, medium-, and low- emissions scenarios. Point estimates derived from these projections are being integrated into on-site surveys to better understand current recreationists' attitudes and contingent behaviors in response to projected climatic and environmental conditions (Objective 4). 


\section{Modeling changes to climate-related variables affecting recreation and tourism}

The project's hydroclimatic models build on the work of Wilson, Sheshukov, and Pulley (2006). It uses Jacobian transformations and first-order analyses to convert historic climate data (e.g., average daily high/low air temperatures and average daily high/low wind chill temperatures) to ecological variables more likely to impact North Shore recreation and tourism (e.g., average daily ice thickness and snow depth). In addition, the project team has compiled monthly visitation data from 1999 to 2013 for eight state parks and one national monument in the project area. These data are currently being regressed on the observed climate and environmental variables to determine the extent to which visitation has historically been influenced by climatic and environmental conditions.

Climatic and environmental variables significantly related to visitation are being projected under high, medium, and, low emissions scenarios (IPCC 2014; Riahi, Grübler, and Nakicenovic 2007; van Vuuren, Weyant, and de la Chesnaye 2006; van Vuuren, Lucas, and Hilderink 2007). The emissions scenarios were obtained from the National Center for Atmospheric Research. Multiple scenarios were developed to account for the uncertainty in climate predictions. To further improve reliability, the scenarios used in this study are being compared to the modeling data produced by climate change studies conducted for the western shore of Lake Superior. The scenarios will be used to produce point estimates that project future climatic and environmental conditions in 2035; these estimates are being employed in on-site surveys to understand North Shore recreationists' contingent trip-taking behavior in relation to projected environmental conditions.

\section{Assessing tourists' risk perceptions and contingent trip-taking behavior}

Seasonal surveys (i.e., winter and summer versions) are being administered at North Shore recreation areas and tourism-dependent businesses to capture differing tourist types and seasonal visitation peaks. A multi-stage sampling plan was used to draw a random sample that captures visitation trends across the week and throughout the day. Although no visitor intercept quotas were established for individual sampling sites, the study aims to gather 1,000 completed surveys in winter and summer 2015. Administering the surveys in two seasons yields a diverse sample of outdoor recreationists; it also provides insight into how shifts in climatic and environmental 
conditions may increase participation in some activities while decreasing participation in others.

The on-site survey will assess tourists' current visitation behaviors, expenditures on their current trip, climate-related risk perceptions specific to the North Shore, contingent trip-taking behavior (in relation to alternative future conditions), and the substitutability of recreational activities on the North Shore (how climate change may affect their recreation participation). The survey instrument was prepared by multiple members of the research team, each providing the expertise necessary to craft reliable, valid survey items measuring a variety of constructs (e.g., economic expenditures, climate change risk perceptions, and place attachment). The research team edited multiple iterations of the instrument, which was then critiqued by members of the participatory advisory team, updated, and piloted with a sample of North Shore tourists. Technical experts unaffiliated with the project were asked to review and evaluate the post-pilot instrument (Vaske 2008).

Contingent trip-taking behavior will be evaluated by presenting individuals with a side-by-side comparison of current seasonal averages for climate and environmental conditions alongside projected future condition averages derived from one of the three emissions scenarios. Soliciting responses about the number of North Shore visits estimated for the current season, as well as expected visitation frequency under future conditions, will allow us to determine if, and how, different emission scenarios will impact nature-based recreation and tourism throughout the region. The substitutability of recreational activities on the North Shore will be gauged by questions specific to place attachment, a concept shown to influence tourist behavior (Smith, Siderelis, and Moore 2010; Dawson, Havitz, and Scott 2011).

\section{Correlate Visitation and Climate Data}

The survey data will be employed in economic modeling to determine the relationship between shifts in climatic and environmental conditions and changes in the demand for outdoor recreation and tourism throughout the region. Observed and contingent visitation counts will be used to fit a random utility model whereby individuals are assumed to maximize personal utility given household budgetary constraints, the travel costs associated with visiting a site, and the site's characteristics (Phaneuf and Smith 2005). Input-output models will also be used to estimate the economic impact of shifts in the demand for outdoor recreation and tourism. Given the intertwined nature of changes in climate and environmental conditions, 
demand for outdoor recreation and tourism, and economic impacts, this multimethods research program provides an integrative framework designed to yield a better assessment of nature-based tourism-dependent communities' climate-related vulnerability.

\section{Takeaway Messages for Practice}

The application of interdisciplinary approaches from the geophysical, social and economic sciences provides a rigorous assessment of community climate readiness. While this project is at the beginning stages, the framework (Table 1 and Figure 2) provides an innovative process that combines hydroclimatic and visitation data to better understand climate-related risks to nature-based recreation and tourism destinations. Not discussed in depth here, but of equal importance, are project objectives to assess North Shore communities' capacity to adapt to climate change (Objective 1 ), and create decision-support tools to enhance adaptation capacity (Objective 5). The decision-support tools will be strategically linked to the most critical recreation and tourism resources identified by North Shore stakeholders during project-related interviews and workshops. In all, the research team's approach reflects the multifaceted nature of climate readiness and is iterative with a replicable framework. Using hydroclimate scenarios to frame the visitor survey and using the visitor survey to inform economic projections captures the inter-relatedness of these components in assessing destination risk and will help North Shore communities to build their climate readiness.

\section{References}

Dawson, Jackie, Mark Havitz, and Daniel Scott. 2011. "Behavioral Adaptation of Alpine Skiers to Climate Change: Examining Activity Involvement and Place Loyalty." Journal of Travel and Tourism Marketing 28: 388-404.

de Freitas, Chris R. 2003. "Tourism Climatology: Evaluating Environmental Information for Decision Making and Business Planning in the Recreation and Tourism Sector." International Journal of Biometeorology 48 (1): 45-54.

de Freitas, Chris R., Daniel Scott, and Geoff McBoyle. 2008. "A Second Generation Climate Index for Tourism (CIT): Specification and Verification." International Journal of Biometeorology 52 (5): 399-407.

Eakin, Hallie, and Amy Lynd Luers. 2006. "Assessing the Vulnerability of Social-Environmental Systems." Annual Review of Environment and Resources 31: 365-394. 
Kelly, Tim. 2005. Ten-year Forecasts of Minnesota Adult Outdoor Recreation Participation, 2004 to 2014. St. Paul: Minnesota Department of Natural Resources.

Noble, Ian R., Saleemul Huq, Yuri A. Anokhin, JoAnn Carmin, Dieudonne Goudou, Felino P. Lansigan, Balgis Osman-Elasha, and Alicia Villamizar. 2014. "Adaptation Needs and Options." In Climate Change 2014: Impacts, Adaptation, and Vulnerability. Part A: Global and Sectoral Aspects. Contribution of Working Group II to the Fifth Assessment Report of the Intergovernmental Panel on Climate Change, edited by Christopher B. Field, Vicente R. Barros, David Jon Dokken, Katharine J. Mach, Michael D. Mastrandrea, T. Eren Bilir, and Monalisa Chatterjee, 833-868. Cambridge and New York: Cambridge University Press.

Phaneuf, Daniel J., and V. Kerry Smith. 2005. "Recreation Demand Models." Handbook of Environmental Economics 2:671-761.

Riahi, Keywan, Arnulf Grübler, and Nebojsa Nakicenovic. 2007. "Scenarios of Long-Term SocioEconomic and Environmental Development under Climate Stabilization.” Technological Forecasting and Social Change 74:887-935.

Smith, Jordan W., Christos Siderelis, and Roger L. Moore. 2010. "The Effects of Place Attachment, Hypothetical Site Modifications, and Use Levels on Recreation Behavior." Journal of Leisure Research 42 (4): 621-640.

van Vuuren, Detlef P., Paul L. Lucas, and Henk Hilderink. 2007. "Downscaling Drivers of Global Environmental Change: Enabling Use of Global SRES Scenarios at the National and Grid Levels." Global Environmental Change 17 (1): 114-130.

van Vuuren, Detlef P., John Weyant, and Francisco de la Chesnaye. 2006. "Multi-Gas Scenarios to Stabilize Radiative Forcing." Energy Economics 28 (1): 102-120.

Vaske, Jerry J. Survey Research and Analysis: Applications in Parks, Recreation and Human Dimensions. State College: Venture Publishing.

Wilson, Bruce, Aleksey Sheshukov, and Reid Pulley. 2006. Erosion Risk Assessment Tool for Construction Sites. St. Paul: Minnesota Department of Transportation. 